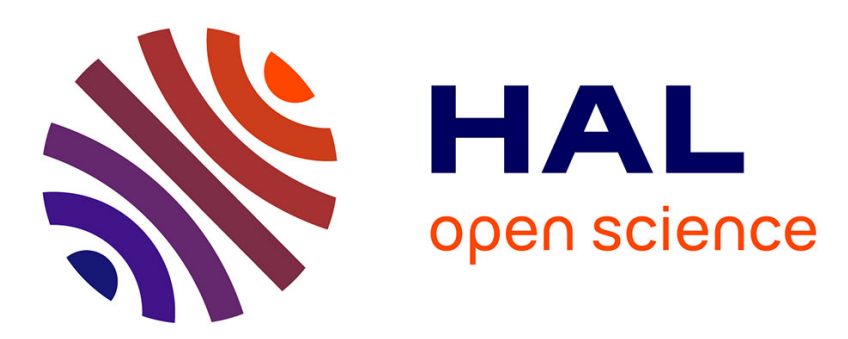

\title{
Sulfur-based electrode using a polyelectrolyte binder studied via coupled in situ synchrotron X-ray diffraction and tomography
}

Quentin Lemarié, Éric Maire, Hassane Idrissi, Pierre-Xavier Thivel, Fannie Alloin, Lionel Roue

\section{To cite this version:}

Quentin Lemarié, Éric Maire, Hassane Idrissi, Pierre-Xavier Thivel, Fannie Alloin, et al.. Sulfur-based electrode using a polyelectrolyte binder studied via coupled in situ synchrotron X-ray diffraction and tomography. ACS Applied Energy Materials, 2020, 3 (3), pp.2422-2431. 10.1021/acsaem.9b02108 . hal-02520782

\section{HAL Id: hal-02520782 \\ https://hal.science/hal-02520782}

Submitted on 26 Mar 2020

HAL is a multi-disciplinary open access archive for the deposit and dissemination of scientific research documents, whether they are published or not. The documents may come from teaching and research institutions in France or abroad, or from public or private research centers.
L'archive ouverte pluridisciplinaire HAL, est destinée au dépôt et à la diffusion de documents scientifiques de niveau recherche, publiés ou non, émanant des établissements d'enseignement et de recherche français ou étrangers, des laboratoires publics ou privés. 
Sulfur-based electrode using a polyelectrolyte binder studied via coupled in situ synchrotron X-ray diffraction and tomography

Quentin Lemarie $^{\mathrm{a}, \mathrm{b}}$, Eric Maire ${ }^{\mathrm{b}}$, Hassane Idrissi $^{\mathrm{b}}$, Pierre-Xavier Thivel $^{\mathrm{c}}$, Fannie Alloin ${ }^{\mathrm{c}}$, Lionel Roué ${ }^{\mathrm{a}, *}$

${ }^{a}$ INRS- Énergie, Matériaux, Télécommunications, Varennes, Québec, J3X 1S2, Canada

${ }^{b}$ Université de Lyon, INSA-Lyon, MATEIS, CNRS UMR5510, F-69621 Villeurbanne, France

${ }^{c}$ Univ. Grenoble Alpes, Univ. Savoie Mont Blanc, CNRS, Grenoble INP, LEPMI, 38000

Grenoble, France

*Corresponding author: roue@emt.inrs.ca (Lionel Roué) 


\begin{abstract}
Polyelectrolytes are promising binders for sulfur cathodes of Li/S batteries, with an ability to control the diffusion of polysulfides into the electrolyte, but their impact on the microstructural evolution of the electrode with cycling is presently unknown. In this study, coupled in situ synchrotron X-ray diffraction and tomography analyses are performed during the $1^{\text {st }}$ and $11^{\text {th }}$ cycles of a sulfur-based electrode made with poly(diallydimethylammonium) bis(trifluoromethane sulfonyl)imide as a polyelectrolyte binder. Sulfur deposited at the end of the $1^{\text {st }}$ charge is mainly $\beta-S_{8}$ but some $\alpha-S_{8}$ is also deposited during the $1^{\text {st }}$ charge on the unreacted $\alpha-S_{8}$ particles. No $\alpha-S_{8}$ is detected at the $11^{\text {th }}$ cycle, suggesting that remaining $\alpha-S_{8}$ reacts progressively with cycling. The carbon-binder domain is not discernible due to spatial and contrast resolution limitations and thus, its evolution with cycling and its specific role on the sulfur dissolution and deposition processes cannot be clearly established. However, the fact that there is no collapsing of the electrode in the sulfur-depleted zones (in contrast to what was observed in literature with a conventional binder such as PVDF) suggests that the present polyelectrolyte is an efficient binder to preserve the electrode architecture upon cycling.
\end{abstract}

Keywords: sulfur electrode, Li/S batteries, polyelectrolyte bonder, in-situ X-Ray tomography, in-situ X-Ray diffraction 


\section{Introduction}

With the inability of today's Li-ion batteries to fully meet electric vehicle (EV) requirements and the rarefaction and high cost of some of its materials, especially cobalt ${ }^{1}$, it has become a necessity to search for a successor to the Li-ion system. For this purpose, the lithium-sulfur (Li/S) system is currently one of the most promising technologies. ${ }^{2}$ Elemental sulfur is both low-cost and abundant and can provide a theoretical specific capacity of 1675 $\mathrm{mAh} \mathrm{g}^{-1}$, leading to a theoretical energy density of $2567 \mathrm{Wh} \mathrm{kg}^{-1}$ for Li/S system versus 387 Wh $\mathrm{kg}^{-1}$ for typical graphite/ $\mathrm{LiCoO}_{2}$ system. ${ }^{3}$ However, the $\mathrm{Li} / \mathrm{S}$ system is based on an entirely different chemistry than Li-ion batteries and faces several issues, such as insufficient cycle life and volumetric energy density, which need to be addressed and resolved before possibility of commercialization.

Charge transfer in Li/S batteries is operated via a series of chemical and electrochemical reactions involving dissolution and precipitation of sulfur species, inducing important morphological changes of the positive electrode. The phase transformation of the positive active material upon discharge (from initial solid $\mathrm{S}_{8}$ to precipitated solid $\mathrm{Li}_{2} \mathrm{~S}$ ) involves going through the formation of soluble species $\left(\mathrm{Li}_{2} \mathrm{~S}_{\mathrm{n}}, 8 \geq \mathrm{n}>2\right){ }^{4}$ The dissolution of these intermediate polysulfide species and their diffusion to the lithium metal electrode can lead to several of the main issues of $\mathrm{Li} / \mathrm{S}$ systems, such a progressive loss of active material, selfdischarge, or "shuttle reactions", causing low coulombic efficiency and reduced cycle life. Therefore, many different ways are investigated in order to get a better control on these mechanisms on a molecular scale, including works on electrolyte composition ${ }^{5}$, separator modifications $^{6}$, or nano-scale sulfur encapsulation. ${ }^{7}$

Polyelectrolytes are polymers composed of ionizable groups charged either positively or negatively. Thanks to their combined polymer and electrolyte properties, they have been used in various applications, among which corrosion protective coatings. ${ }^{8,9}$ In a recent work ${ }^{10}$, the 
usability of polyelectrolyte binders for sulfur-based electrodes has been demonstrated and have shown highly promising performance in terms of capacity retention and rate capability at high areal sulfur loading, making their operation possible with high accessible capacity (up to $\sim 8 \mathrm{mAh} \mathrm{cm}^{-2}$ ) at high $\mathrm{C}$-rates (up to $2 \mathrm{C}$ ) and with high areal sulfur loadings (up to $8.1 \mathrm{mg}$ $\mathrm{cm}^{-2}$ ). This is related to the ability of the cationic polyelectrolyte binder to $(i)$ restrict the diffusion of soluble polysulfide species from the porous carbon sulfur host into the electrolyte due to the preferential and strong electrostatic interactions of the lithium polysulfides with the cationic polymer backbone and (ii) facilitate the lithium ion transport in the sulfur electrode thanks to the reconfigurable network of mobile anions associated with the cationic polymer backbone. On the other hand, the binder can also have a major influence of the mechanical properties (adhesion and cohesion strengths) of the electrode, which are likely to impact on the morphological degradation of the electrode (e.g. collapse, delamination from the current collector) associated with the sulfur dissolution upon cycling. To the best of our knowledge, the impact of the polyelectrolyte type binder on the morphological evolution during cycling of sulfur electrodes has never been evaluated.

In situ X-ray diffraction (XRD) and X-ray computed tomography (XRCT) are without contest some of the most powerful analytical tools to characterize the structural and morphological changes of battery electrodes upon cycling. ${ }^{11}$ XRCT is a non-destructive 3D imaging technique that enables the extraction of crucial quantitative parameters such as volume fraction, size distribution, tortuosity or connectivity of the different phases inside the electrodes. In order to access those parameters, the different phases (e.g. active material, carbon and binder additives, electrolyte, current collector, separator) need to be differentiated ("segmented") through image processing and analytical procedures. The use of a synchrotron X-ray source not only enables phase contrast imaging, which accentuates the differentiation, 
but also grants a better spatial resolution (few tens of nm versus few $\mu \mathrm{m}$ for laboratory X-ray sources) and shorter acquisition times.

For the past years, in situ laboratory $\mathrm{XRD}^{12-15}$, and in situ synchrotron $\mathrm{XRD}^{16-23}$ have been used to monitor the evolution of crystalline sulfur species in various positive electrode formulations. In most studies, diffraction peaks from $\alpha-S_{8}$ and $\beta-S_{8}$ are identified and their evolution is quantified during discharge and charge. In some cases, $\mathrm{Li}_{2} \mathrm{~S}$ peaks were also identified $^{13,16,21}$, and in some more rare cases, polysulfide species were observed. ${ }^{17,24}$ Although in situ synchrotron XRCT has been used by many groups to characterize lithiumion battery electrodes, such as silicon-based anodes ${ }^{25,26}, \mathrm{LiCoO}_{2}{ }^{27}$ or $\mathrm{NMC}^{28}$ positive electrodes, it is only very recently that S-based electrodes have started to be investigated. ${ }^{29-}$ ${ }^{31,19}$ Yermukhambetova et al. studied sulfur evolution at a nanometric scale in conventional electrodes. ${ }^{29}$ Zielke et al. were able to follow the dissolution and deposition of sulfur inside a porous carbon electrode. ${ }^{30}$ Tonin et al. confirmed these observations by combining operando XRCT with XRD and also characterizing the morphological changes in the lithium anode. ${ }^{31}$ Yu et al. combined several X-ray based techniques to follow the evolution of sulfur clusters as well as $\mathrm{Li}_{2} \mathrm{~S}$ formation and the influence of current density. ${ }^{19}$

In the present work, a sulfur cathode integrating a polyelectrolyte binder (poly(diallydimethylammonium) bis(trifluoromethane sulfonyl)imide) is studied by coupled in situ synchrotron XRD and XRCT performed during the $1^{\text {st }}$ and $11^{\text {th }}$ cycles. Those techniques were chosen in order to assess if the use of this polyelectrolyte binder has an impact on the electrode morphology evolution during cycling and degradation, on top of its aforementioned advantageous properties. The sulfur dissolution and deposition processes are observed and their occurrence depending on the cycling stage, spatial position in the electrode and size of the sulfur particles is highlighted. The absence of electrode collapsing in the sulfur-depleted zones is also highlighted. 


\section{Experimental}

\subsection{Polyelectrolyte binder synthesis}

The polyelectrolyte binder used in this work was a poly(diallydimethylammonium) bis(trifluoromethane sulfonyl)imide, abbreviated PDDA-TFSI. It is obtained by exchanging the $\mathrm{Cl}^{-}$anion of PDDACl with the TFSI $^{-}$anion of LiTFSI. ${ }^{10,32}$ To do so, $2.4 \mathrm{~g}$ (0.015 monomer mole) of PDDACl solubilized in water (20 wt $\%$, Sigma-Aldrich) was mixed with $5 \mathrm{~g}$ (0.017 mole) of LiTFSI salt (99.95\%, Sigma-Aldrich) and $150 \mathrm{~mL}$ of deionized water and was stirred for 72 hours. A dense and insoluble light-colored precipitate formed in the mix, which was centrifuged allowing the supernatant solution to be removed. The obtained precipitate was then quickly dried and was mixed again with $2 \mathrm{~g}(0.007$ mole $)$ of LiTFSI in $80 \mathrm{~mL}$ of acetone, ensuring the full completion of the anionic exchange reaction, as confirmed from ${ }^{19}$ F NMR analysis (not shown). After 12 hours of stirring, the mixture was concentrated by evaporating the acetone. It was then precipitated in $500 \mathrm{~mL}$ of deionized water under stirring for several hours, before being filtered and dried.

\subsection{Materials and electrode preparation}

The synthetized PDDA-TFSI was used as a binder material in composite sulfur electrodes. As received sulfur (S) powder (-325 mesh, 99.5\%, Alfa Aesar) was used as active material and carbon black (CB) (Super P Li, Timcal) as a conductive additive. The electrode composition was fixed to 70/20/10 wt\% (S/CB/binder). An aluminum foil $(20 \mu \mathrm{m}$ thick, MTI) was used as current collector. Polyvinylidene difluoride (PVdF) and carboxymethylcellulose (CMC) binders were also used in composite electrodes to compare the electrochemical performance of the different binders. Depending of the nature of their binder (PDDA-TFSI, PVdF and CMC), the three electrodes formulations were respectively labelled as PDDA, PVdF and CMC. 
$\mathrm{S}$ and $\mathrm{CB}$ powders were manually ground in an agate mortar for 15 minutes with addition of a few drops of cyclohexane in order to get a homogeneous composite. After evaporation of the cyclohexane, the resulting $\mathrm{S}+\mathrm{CB}$ powder was recovered. The PDDA-TFSI binder was weighed and dissolved in N-methyl-2-pyrrolidone (NMP) (anhydrous, 99.5\%, Sigma Aldrich) until a $12 \mathrm{wt} \%$ solution was obtained. It was then poured into a silicon nitride vial along with three silicon nitride milling balls, to which the S+CB powder was added. The slurry was mixed using a Fritsch Pulverisette 7 mixer at $500 \mathrm{rpm}$ for 1 hour. The resulting homogenized ink was coated onto the Al current collector using a doctor-blade technique, where the blade gap was tailored in order to keep the areal sulfur loading of the electrodes as constant as possible. A blade gap of $300 \mu \mathrm{m}$ gave a dry coating of $70 \pm 5 \mu \mathrm{m}$ with a sulfur loading of $2 \pm 0.3 \mathrm{mg}_{\text {sulfur }} \mathrm{cm}^{-2}$. The electrodes were dried at $60^{\circ} \mathrm{C}$ for 24 hours in a vacuum oven before being cut into discs (Ø14 $\mathrm{mm}$ for coin cells and $\varnothing 2.5 \mathrm{~mm}$ for synchrotron cells) and stored in an argon-filled glove-box. PVdF and CMC-based electrodes were constructed in a similar way as described in our previous work. ${ }^{33}$

\subsection{Cell assembly}

Conventional CR2032 two-electrode coin cells were used for the electrochemical testing of the electrodes. The cells were assembled in the glove box by stacking the sulfur electrode, a thick polyolefin non-woven tissue (Viledon, Freudenberg) serving as electrolyte reservoir and separator, a polypropylene separator (Celgard 2400) and a disc of lithium metal (MTI) serving as counter and reference electrode. The selected electrolyte had a standard composition of $1 \mathrm{M}$ LiTFSI and $0.1 \mathrm{M}$ lithium nitrate additive (Aldrich) dissolved in a $1 / 1$ volume ratio mixture of tetraethylene glycol dimethyl ether (TEGDME, 99\%, Aldrich) and 1,3-dioxolane (DIOX, anhydrous, $99.8 \%$, Aldrich). $150 \mu \mathrm{L}$ of electrolyte was poured onto the working electrode and the separators in order to completely soak the porosities of all the materials. 
The cell used for in situ synchrotron XRCT/XRD measurements was a two-electrode Swagelok cell inspired from previous similar experiments in our group on Si-based electrodes. ${ }^{25}$ As schematized in Figure 1, the S-based electrode diameter was $2.5 \mathrm{~mm}$. The casing of the cell was made of perfluoroalkoxy alkane (PFA) polymer with a reduced wall thickness near the electrodes in order to lower X-ray attenuation during experiments. The positive sulfur electrode was placed onto an additional thick aluminum cylinder to avoid stainless steel connector to be visible in the imaged zone. A spring placed on the negative electrode side ensured the compression and the electrical contact of the cell components.

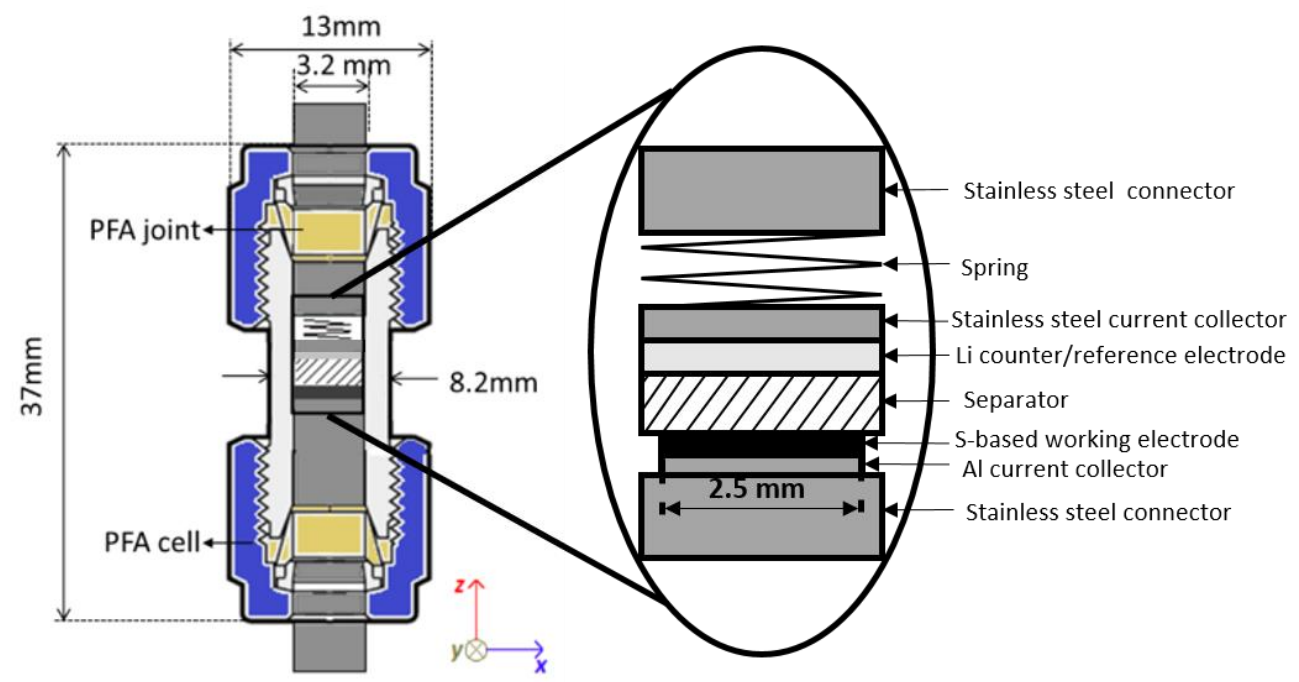

Figure 1. Schematic diagram of the electrochemical cell used for in situ synchrotron XRCT/XRD experiments

\subsection{Electrochemical measurements}

Coin cell cycling experiments were performed on a BTS4000 (Neware) battery cycler. For synchrotron experiments, a SP-300 potentiostat/galvanostat (Bio-Logic Science Instruments) was used. The cells were galvanostatically cycled between 1.5 and $3.0 \mathrm{~V}$ at a rate of $\mathrm{C} / 50$ or $\mathrm{C} / 20$. The values of the applied current were calculated based on the loading of each electrode and the theoretical capacity of sulfur $\left(1675 \mathrm{mAh} \mathrm{g}^{-1}\right)$. The capacities are expressed in mAh per $g$ of sulfur. 


\subsection{In situ synchrotron $X$-ray tomography and $X$-ray diffraction}

In situ synchrotron XRCT and XRD measurements were performed on beamline ID11 at the European Synchrotron Radiation Facility (ESRF) (Grenoble, France). XRCT and XRD analyses were successively carried out every 30 minutes during the $1^{\text {st }}$ and $11^{\text {th }}$ cycles. The cell was cycled at $\mathrm{C} / 20$ and was set to open circuit potential (OCP) during the acquisition of the radiographs and diffraction patterns. The acquisition time of XRCT was $\sim 15 \mathrm{~min}$ and $\sim 2$ min for XRD, with $\sim 2$ min for switching between the two configurations.

The tomography detector was coupled via an optical microscope to a thin phosphor scintillator. The diffraction detector used a fiber optic taper and a thicker phosphor scintillator. ${ }^{34}$ The energy of the monochromated beam was set at $38 \mathrm{keV}(\lambda=0.0326 \mathrm{~nm})$ and a beam size of $1 \times 1 \mathrm{~mm}^{2}$ for XRCT. The PyHST2 software ${ }^{35}$ was used to reconstruct the 3D tomographic volumes of $1433 \times 1433 \times 490 \mu \mathrm{m}^{3}$ with an isotropic voxel size of $0.7 \mu \mathrm{m}$ (meaning a spatial resolution of about $1.4 \mu \mathrm{m}$ ). The dimensions of the imaged zone were calibrated to cover the whole active height of the cell, from the aluminum current collector on the positive electrode side to the stainless steel collector on the lithium electrode side. In order to reduce the size of the image stacks and facilitate the image analyses, the studied zone was subsequently cropped from the bottom of the positive electrode up to the separator, corresponding to an analyzed volume of $1433 \times 1433 \times 70 \mu \mathrm{m}^{3}$. The grayscale values in the presented pictures correspond to the attenuation coefficient, therefore denser and more attenuating regions appear brighter. All image processing and quantitative analyses were performed using the Fiji software. ${ }^{36}$

The XRD detector was placed at a distance of $25 \mathrm{~cm}$ of the sample. The energy of the beam was the same as XRCT measurements, and the incident beam size was restricted down to $50 \times 50 \mu \mathrm{m}^{2}$ at FWHM. A total of 20 successive $2 \mathrm{D}$ XRD images were obtained for each 
cycling step, one diffraction scan being acquired in $20 \mu \mathrm{m}$ steps along the vertical axis of the electrochemical cell. This way, the whole active height of the cell was covered, from the Al current collector on the positive electrode side up to the stainless steel collector on the negative electrode side. The 2D XRD pictures were integrated to obtain full XRD patterns. The background signal was measured on an empty Swagelok cell and was removed by subtraction from the XRD patterns.

\section{Results and discussion}

\subsection{Electrochemical performance}

The electrochemical performance of the electrode fabricated using polyelectrolyte PDDA binder was compared to the two more conventional formulations ( $\mathrm{PVdF}$ and $\mathrm{CMC}$ ) by cycling of coin cells at C/50 at room temperature. Figure 2a shows the evolution of the specific discharge capacities of all three formulations during 50 cycles. As already shown in our previous work ${ }^{33}$ and in the literature ${ }^{37}, \mathrm{PVdF}$ and CMC formulations show similar performance, with an initial discharge capacity of respectively $640 \mathrm{mAh} \mathrm{g}^{-1}$ and $610 \mathrm{mAh} \mathrm{g}^{-1}$, quickly dropping during the first ten cycles to reach a value around $250 \mathrm{mAh} \mathrm{g}^{-1}$ after 50 cycles. On the other hand, the PDDA formulation presents an improved initial discharge capacity of $1050 \mathrm{mAh} \mathrm{g}^{-1}$ with a lower capacity decay upon cycling to reach a nearly stable discharge capacity of $730 \mathrm{mAh} \mathrm{g}^{-1}$ after 50 cycles, hence almost 3 times the capacity of the previous formulations. These results are in accordance with the study of Li et al. showing a higher initial capacity and a better capacity retention during prolonged cycling of S-based electrode with polyelectrolyte PDDA-TFSI binder compared to conventional PVdF binder. ${ }^{10}$ 

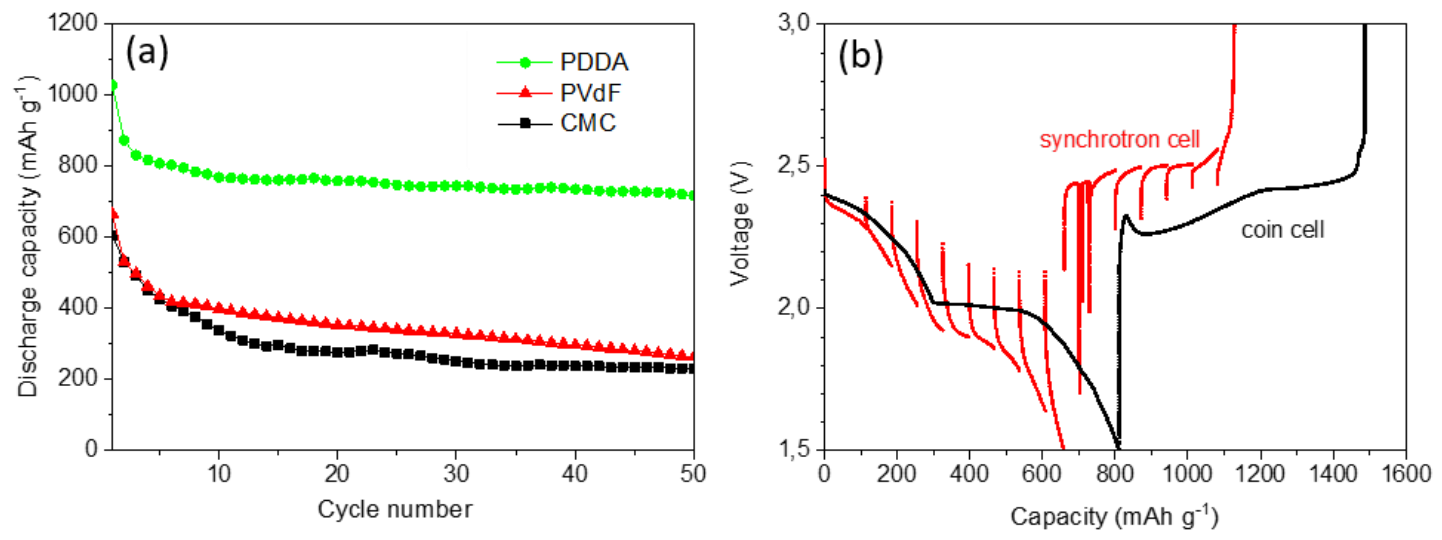

Figure 2. (a) Evolution with cycling of the discharge capacities of PDDA, PVDF and CMC electrodes cycled in coin cell at C/50 and (b) First discharge/charge curves of a PDDA electrode cycled in coin cell and synchrotron cell at C/20. In all cases, the electrode loading is $2 \pm 0.3 \mathrm{mg}_{\text {sulfur }} \mathrm{cm}^{-2}$.

Figure $2 \mathbf{b}$ compares the voltage profiles of the PDDA electrode at $C / 20$ during the $1^{\text {st }}$ cycle performed in a CR2032 coin cell and in the synchrotron cell used for XRD and XRCT experiments. The interruptions in the voltage profile of the synchrotron cell correspond to the XRD-XRCT acquisition steps during which the cell was let in open circuit. These OCP periods of $\sim 20$ min per acquisition step are deleted in Figure $\mathbf{2 b}$. First, it can be seen that the initial discharge capacity of the coin cell at $\mathrm{C} / 20$ is lower than at $\mathrm{C} / 50$, here reaching $810 \mathrm{mAh} \mathrm{g}^{-1}$ (vs. $1050 \mathrm{mAh} \mathrm{g}^{-1}$ at $\mathrm{C} / 50$ in Figure 2a). The discharge capacity of the synchrotron cell at $\mathrm{C} / 20$ is lower, with an initial value of $660 \mathrm{mAh} \mathrm{g}^{-1}$. Most of the difference in the discharge capacities of the two cell configurations resides in the length of the second discharge plateau, noticeably shorter for the synchrotron cell. During this plateau, the polysulfide species $\left(\mathrm{Li}_{2} \mathrm{~S}_{\mathrm{n}}, 8 \geq \mathrm{n}>2\right)$ dissolved in the electrolyte are reduced in shorter polysulfide chains and solid products $\mathrm{Li}_{2} \mathrm{~S}_{2} / \mathrm{Li}_{2} \mathrm{~S}$ are formed. A shorter plateau can mean a lower amount of solid products being precipitated associated with an incomplete reduction reaction. The charge capacity of the synchrotron cell is also noticeably smaller, i.e. $470 \mathrm{mAh}$ $\mathrm{g}^{-1}$ compared to $680 \mathrm{mAh} \mathrm{g}^{-1}$ with the coin cell. A possible explanation is that some dissolved 
polysulfides diffuse outside the electrode during the successive OCP periods (cumulated duration of $\sim 6 \mathrm{~h}$ over the first discharge/charge period of $\sim 14 \mathrm{~h}$ ) and thus become inaccessible for further electrochemical reaction. However, cycling experiments performed with the synchrotron cell but without current interruption periods display similar performance (not shown). Actually, as evidenced in Figure 2b, the electrode polarization is much higher with the synchrotron cell than with the coin cell, resulting in a less deep (incomplete) discharge. Its higher polarization resistance may be due to an imperfect contact of the Selectrode with the current collector because of its small size and the lower compression of the cell, as this phenomenon has been observed on all our tested synchrotron cells, whatever the sulfur electrode formulation. In particular, a homogenous pressure inside the synchrotron cell is more difficult to control due to the reduced size of the electrodes ( $2.5 \mathrm{~mm}$ diam.) even if a spring has been used. This is also in accordance with the presence of an inactive zone at the center area of the S-based electrode in the synchrotron cell, as shown below from the XRCT analysis.

\subsection{In situ synchrotron $X$-ray diffraction}

Figure 3a-b shows the evolution of the diffraction patterns focused on the 3.0-4.0 $\AA \mathrm{d}$ spacing region during the $1^{\text {st }}$ and $11^{\text {th }}$ cycles respectively, along with the corresponding voltage profiles. The patterns obtained during discharge and charge are represented in blue and red respectively. Figure 3c-d are color maps of the evolution of the XRD peak intensities upon cycling. 
(a)

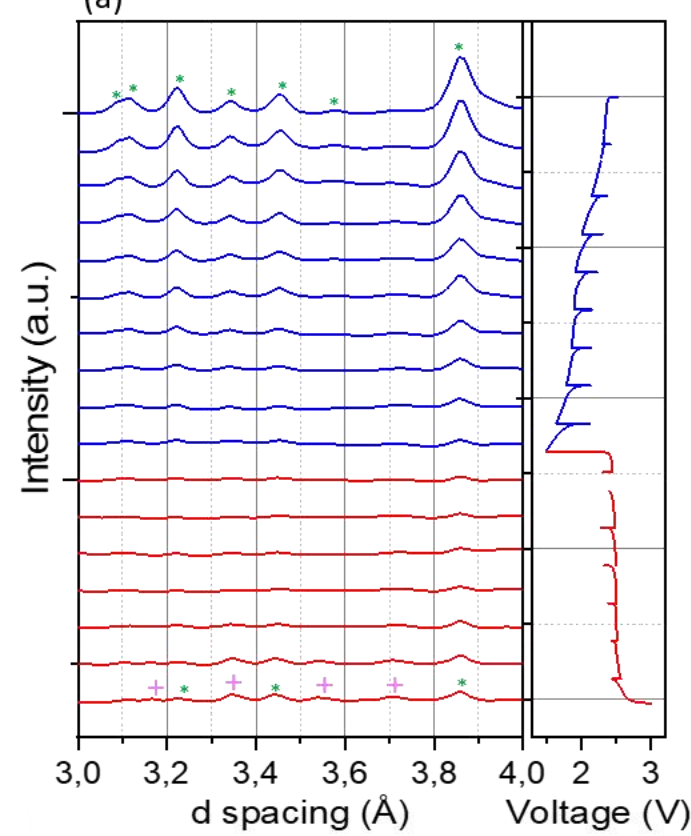

(c)

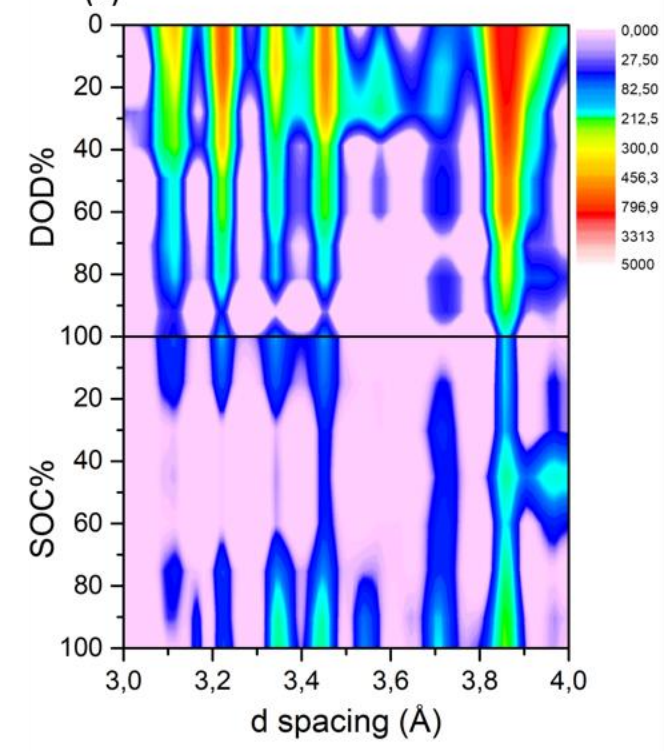

(b)

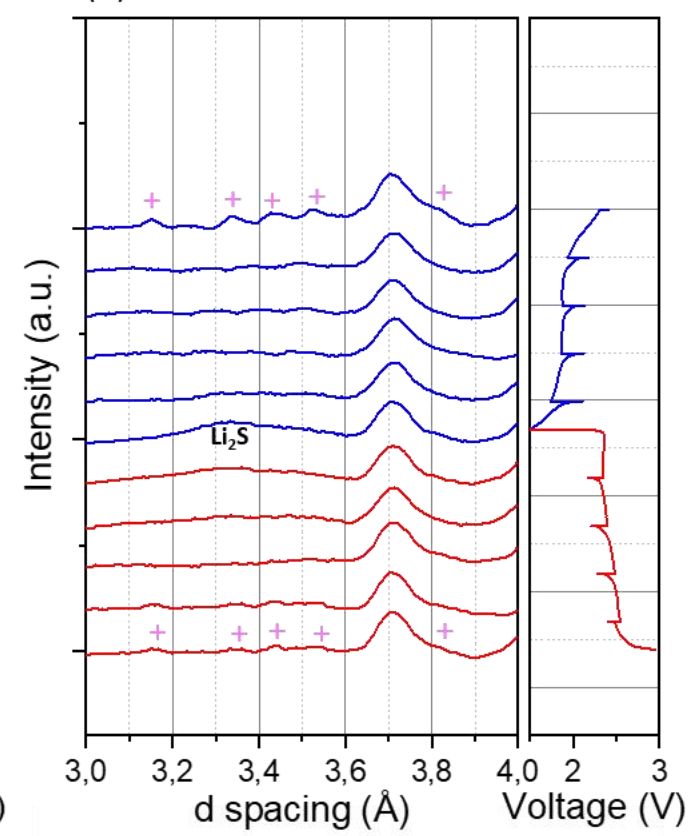

(d)

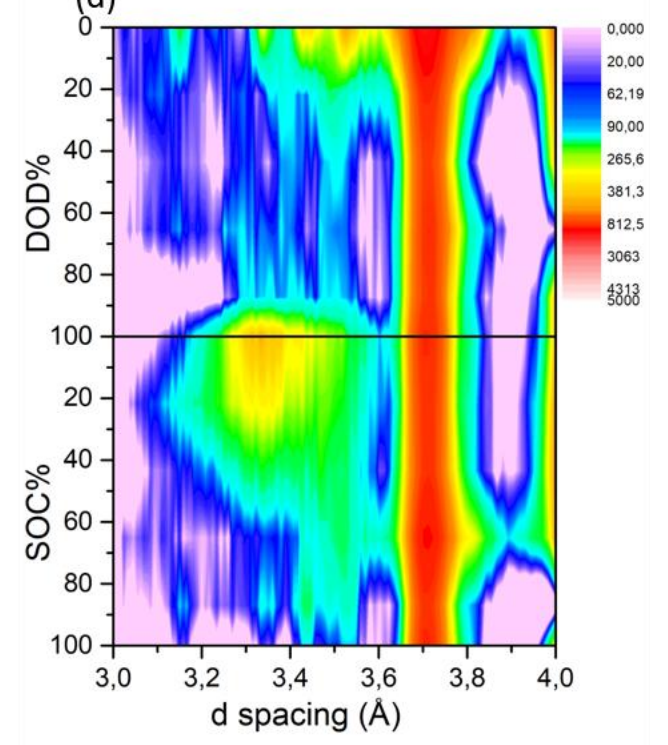

Figure 3. XRD patterns acquired during the $1^{\text {st }}$ cycle $(a)$ and $11^{\text {th }}$ cycle $(b)$ and color intensity mapping of corresponding patterns $(c, d)$

At the initial state, the observed XRD peaks can be attributed to $\alpha-S_{8}$ and are marked with a (*) symbol in Figure 3a. In accordance with JCPDS 01-078-1888, these peaks can be observed at $3.09 \AA\left(\alpha-S_{8}(135)\right), 3.12 \AA\left(\alpha-S_{8}(313)\right), 3.22 \AA\left(\alpha-S_{8}(117)\right), 3.34 \AA\left(\alpha-S_{8}(311)\right)$, $3.45 \AA\left(\alpha-S_{8}(026)\right), 3.57 \AA\left(\alpha-S_{8}(133)\right)$ and $3.86 \AA\left(\alpha-S_{8}(222)\right)$. The intensity of those peaks decreases along the whole discharge. This is highlighted in Figure 4, which displays the relative variation of the added $\alpha-S_{8}$ peak areas as a function of the depth-of-discharge (DOD) 
and state-of-charge (SOC) levels during the $1^{\text {st }}$ cycle. The $\alpha-S_{8}$ dissolution mainly occurs during the first plateau (first 4 steps of discharge) but is also observed during the second discharge plateau and is not fully completed at the end of the $1^{\text {st }}$ discharge. This result differs from the study of Tonin et al. ${ }^{31}$ showing from operando synchrotron XRD analyses the complete disappearance of the $\alpha-S_{8}$ peaks during the $1^{\text {st }}$ discharge plateau. As previously said, this may be associated with some contact problem in our synchrotron cell, impacting on its discharge efficiency. No $\mathrm{Li}_{2} \mathrm{~S}$ peak can be detected at the end of the discharge. It can be explained by the low degree of crystallinity of the formed $\mathrm{Li}_{2} \mathrm{~S}$ that can preclude its clear detection by XRD. ${ }^{38}$ This can also indicate an incomplete polysulfide reduction with the preferential formation of amorphous $\mathrm{Li}_{2} \mathrm{~S}_{2}$ instead of crystalline $\mathrm{Li}_{2} \mathrm{~S}$, in accordance with the low discharge capacity extracted from the $2^{\text {nd }}$ plateau region $\left(\sim 350 \mathrm{mAh} \mathrm{g}^{-1}\right)$. At the very end of the $1^{\text {st }}$ charge (starting around $70 \%$ of SOC), $\beta-S_{8}$ peaks, marked with a $(+)$ symbol in Figure 3a, appear at $3.16 \AA\left(\beta-S_{8}(311)\right), 3.34 \AA\left(\beta-S_{8}(103)\right), 3.53 \AA\left(\beta-S_{8}(122)\right)$ and $3.70 \AA$ $\left(\beta-\mathrm{S}_{8}(-122)\right)$ in accordance with JCPDS 01-077-6252, even though a constant slight shift of about $0.04 \AA^{-1}$ can be noticed in the XRD observations. This shift only affects $\beta-S_{8}$. Hence, the fact that both $\alpha-S_{8}$ and $\beta-S_{8}$ are crystallized at the same time may induce compatibility stresses inside the metastable $\beta-S_{8}$, possibly causing the observed shift in the $\beta-S_{8}$ peaks. Some of the initial $\alpha-S_{8}$ peaks also gain slightly in intensity at the end of the charge (Figure 4), which is unexpected. As discussed below from the XRCT data, it might be related to the presence of unreacted $\alpha-S_{8}$ in the electrode, acting as nucleation sites for the partial oxidation of the polysulfides in $\alpha-S_{8}$ instead of $\beta-S_{8}$. 


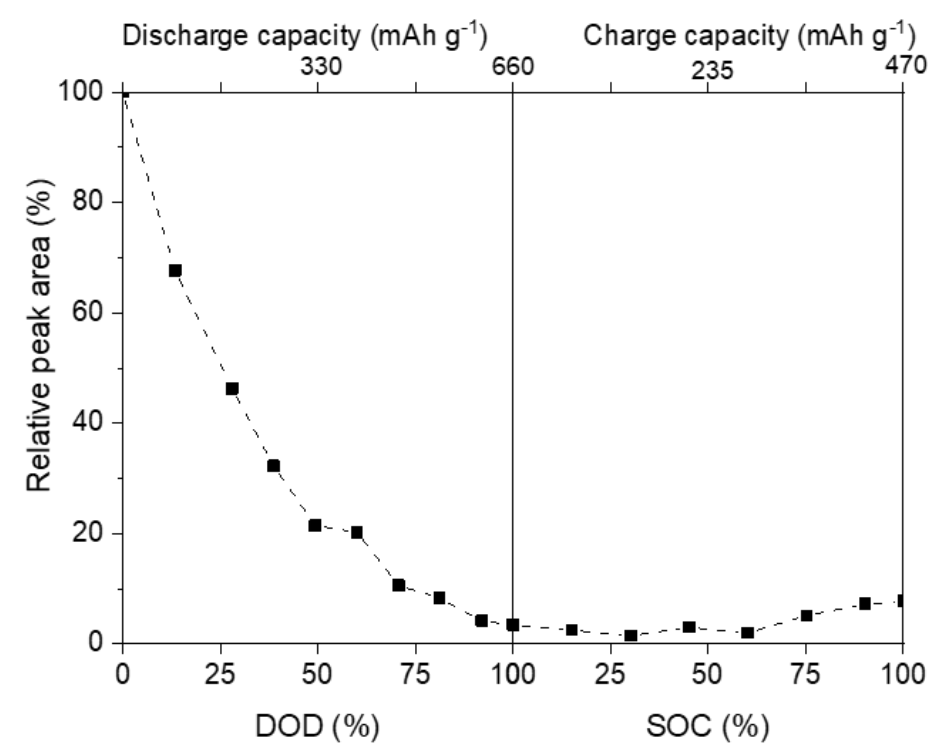

Figure 4. Evolution of the the added $\alpha-S_{8} X R D$ peak area during the $1^{\text {st }}$ cycle

Figure $3 \mathbf{b}$ presents the evolution of the diffraction peaks of the same PDDA electrode during its $11^{\text {th }}$ cycle. Most of the peaks detected at 0\% DOD and 100\% SOC can be attributed to the $\beta-S_{8}$ phase. There is no clear evidence of the presence of the $\alpha-S_{8}$ phase, suggesting that most of the $\alpha-S_{8}$ remaining at the end of the $1^{\text {st }}$ cycle has reacted progressively during the following cycles and was redeposited as $\beta-\mathrm{S}_{8}$ at the end of each charge. A wide "peak" centered at around $3.3 \AA^{-1}$ appears at $\sim 90 \%$ of DOD and remains through the beginning of the charge. This wide peak is here attributed to $\mathrm{Li}_{2} \mathrm{~S}$ (111) identified at $3.28 \AA^{-1}$ in accordance with JCPDS 01-077-2874. The presence of partly crystalline $\mathrm{Li}_{2} \mathrm{~S}$ at the $11^{\text {th }}$ cycle indicates that the polysulfide species have been more completely reduced into crystalline $\mathrm{Li}_{2} \mathrm{~S}$ during the second discharge plateau, compared to the $1^{\text {st }}$ cycle. Finally, an intense peak can be observed at around $3.7 \AA$ in Figure 3c-d, which is associated with another intense peak detected at about $4.1 \AA$ (not shown). No significant evolution in their intensity can be noticed during the $11^{\text {th }}$ cycle. However, their intensity varies depending on the XRD acquisition area along the vertical axis of the cell, with a maximal intensity observed near the $S$ cathode/separator interface, as shown in Figure S1 in supplementary information. Note that these two peaks were also detected at the $1^{\text {st }}$ cycle but with a lower intensity. Their origin is 
presently unclear but they could result from the reaction of the polysulfides with the cell casing.

\subsection{In situ synchrotron $X$-ray tomography}

Figure 5a-c shows the evolution of a selected lateral (i.e. parallel to the current collector) slice of the positive electrode during the $1^{\text {st }}$ cycle at different states of discharge and charge, namely at the initial state (0\% DOD), at the end of the discharge (100\% DOD) and at the end of the charge (100\% SOC). The cross-section view of the electrode is also represented below each lateral image, with the aluminum current collector being visible in light gray. Video S1 in supporting information shows the evolution of these lateral and transversal views during the whole $1^{\text {st }}$ cycle. The lateral slice was selected to be representative of the morphological evolution of the electrode and is close to the interface with the separator. As mentioned in the experimental section, lighter elements appear in a brighter gray. Four different phases can be identified on these images: (i) the fibers of the separator in the darker gray level; (ii) the large sulfur particles or particle clusters (i.e. with a diameter higher than $\sim 2 \mu \mathrm{m}$ ) in white; (iii) the sulfur-rich phase in light gray, containing the lower diameter sulfur particles not distinguishable from the binder, carbon black and submicrometric pores/interstices due to spatial resolution limitation but the sulfur presence is indicated by the overall lighter gray level of the region and (iv) the porous sulfur-free phase in mid-tone gray, filled with electrolyte and also containing the undiscernible binder and carbon black. 

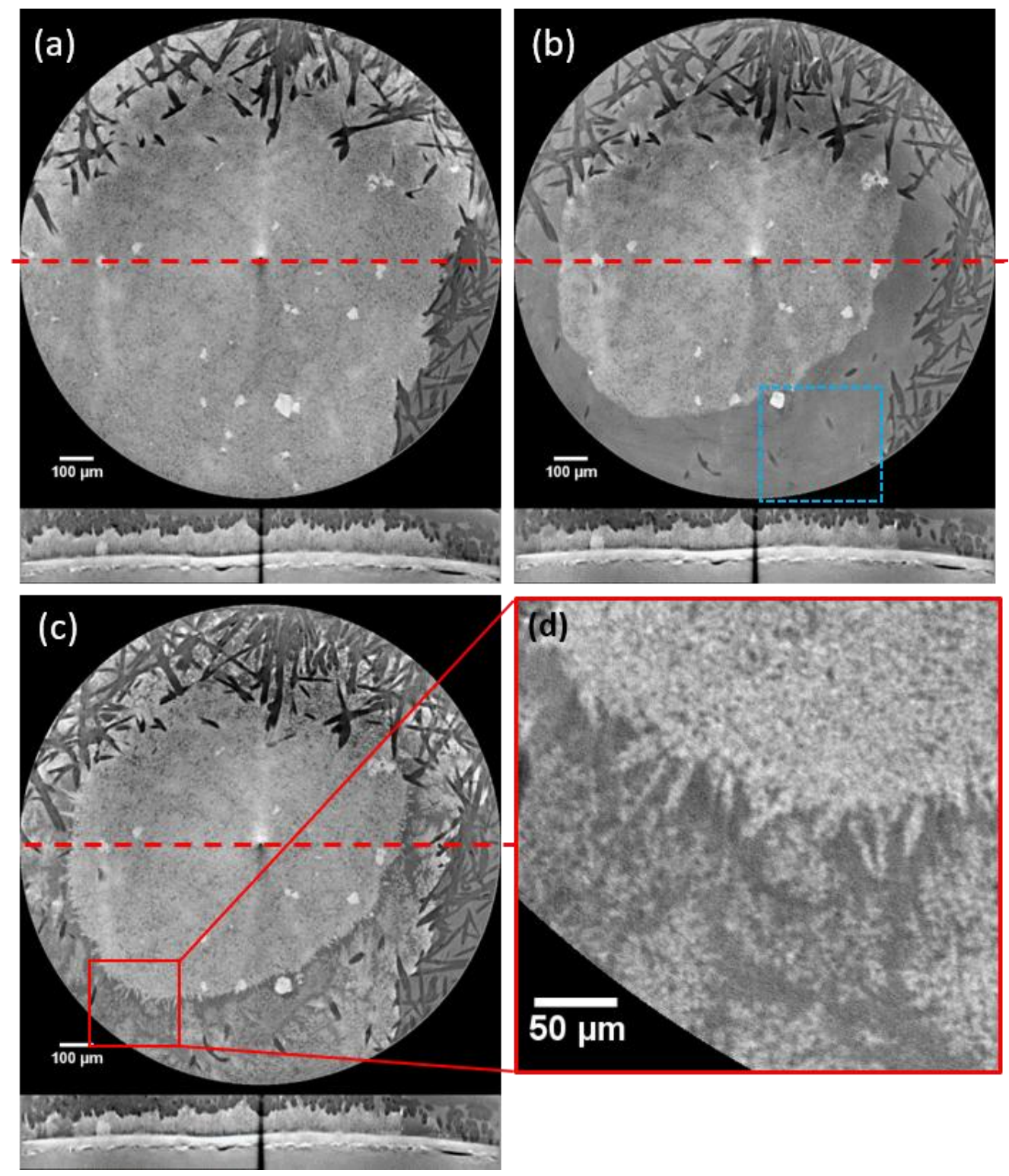

Figure 5. Lateral and transversal XRCT images of the electrode at (a) 0\% DOD, (b) 100\% DOD and (c) 100\% SOC of the $1^{\text {st }}$ cycle. (d) Enlargement of (c). The red dashed line in the lateral images corresponds to the position of the transversal images. The blue square corresponds to the selected active zone shown in Fig. 6.

It can be seen in Figure 5a that at $0 \%$ of DOD, most of the imaged area is occupied by the sulfur containing phase, where bigger sulfur particles are also visible. Some fibers from the separator are visible, as the chosen slice is located close to the electrode-separator interface. The porosity of the electrode appears mostly filled with electrolyte, as no gas phase (likely to be visible in black) can be identified. In Figure 5b (100\% DOD), it can be observed that a lot of the sulfur phase has been dissolved, leaving the porous carbon-binder domain 
(CBD) filled with electrolyte. The size of some of the larger sulfur particles visible in this dissolved area have also been reduced during the discharge process. However, it can be seen that a large area of sulfur-rich phase situated at the center of the electrode remains at the end of the discharge, suggesting that this zone is not electrochemically active during the first discharge. This is in accordance with our previous XRD observation showing some $\alpha-S_{8}$ remaining at the end of the $1^{\text {st }}$ discharge. This inactive zone (also observed in other cells using different binder formulation) may originate from the uneven surface of the aluminum current collector conjugated to an insufficient compression of the synchrotron cell, resulting in an imperfect contact of the electrode film on the $\mathrm{Al}$ current collector. Based on the volume of the segmented sulfur-rich region at the end of the $1^{\text {st }}$ discharge, the inactive portion of the electrode corresponds to around $40 \%$ of the observed volume. Considering that the observed volume represents $\sim 33 \%$ of the whole electrode volume, the inactive zone represents $\sim 13 \%$ of the whole electrode volume, assuming there is no other inactive zone in the part of the electrode which is not observed. This partly explains the difference in the initial discharge capacity between the synchrotron cell and the coin cell. As it can be seen in Video S1, the dissolution of the sulfur phase starts from the edges of the electrode and moves inwards to its center. Considering the very slow lateral displacement rate of the front dissolution $\left(\sim 40 \mu \mathrm{m} \mathrm{h}^{-}\right.$ ${ }^{1}$ ), it can be hardly explained by some difference in Li-ion diffusivity depending on their lateral position in the electrode. This unexpected phenomenon may rather indicate the present of a potential gradient in the electrode resulting from the higher contact resistance at the electrode center.

As mentioned in the XRD results section, it is unclear whether $\mathrm{Li}_{2} \mathrm{~S}$ was formed at the end of the $1^{\text {st }}$ discharge. However, due to its nanometric size, it could not be visible on the tomography images because of resolution limitations and has not yet been directly observed by XRCT in the literature. The deposition of $\beta-S_{8}$ during discharge is clearly observable in 
Figure 5c and Video S1. This deposition starts again from the edges of the electrode and progresses inwards. It can also be seen that the $\beta-S_{8}$ follows a deposition pattern, where deposited sulfur acts as preferred nucleation sites, forming elongated agglomerates as shown in the enlarged image (Figure 5d). Supporting this assertion, part of the sulfur deposition also starts from the edges surrounding the inactive central zone and on the incompletely dissolved larger sulfur particles. This is also in agreement with the XRCT observations of Yermukhambetova et al., suggesting that the remaining sulfur particles deep within the electrode act as favorable nucleation sites for sulfur deposition. ${ }^{29}$ Furthermore, as mentioned in the XRD experiments section, if most of the deposited sulfur at the end of the charge is $\beta$ $\mathrm{S}_{8}$, some $\alpha-\mathrm{S}_{8}$ also seems to have been electrodeposited during the charge. This could mean that the sulfur electrodeposited onto remaining $\alpha-\mathrm{S}_{8}$, which did not react during the discharge, follows the same crystalline pattern and is electrodeposited as orthorhombic $\alpha-\mathrm{S}_{8}$.

(a)

(b)

(c)

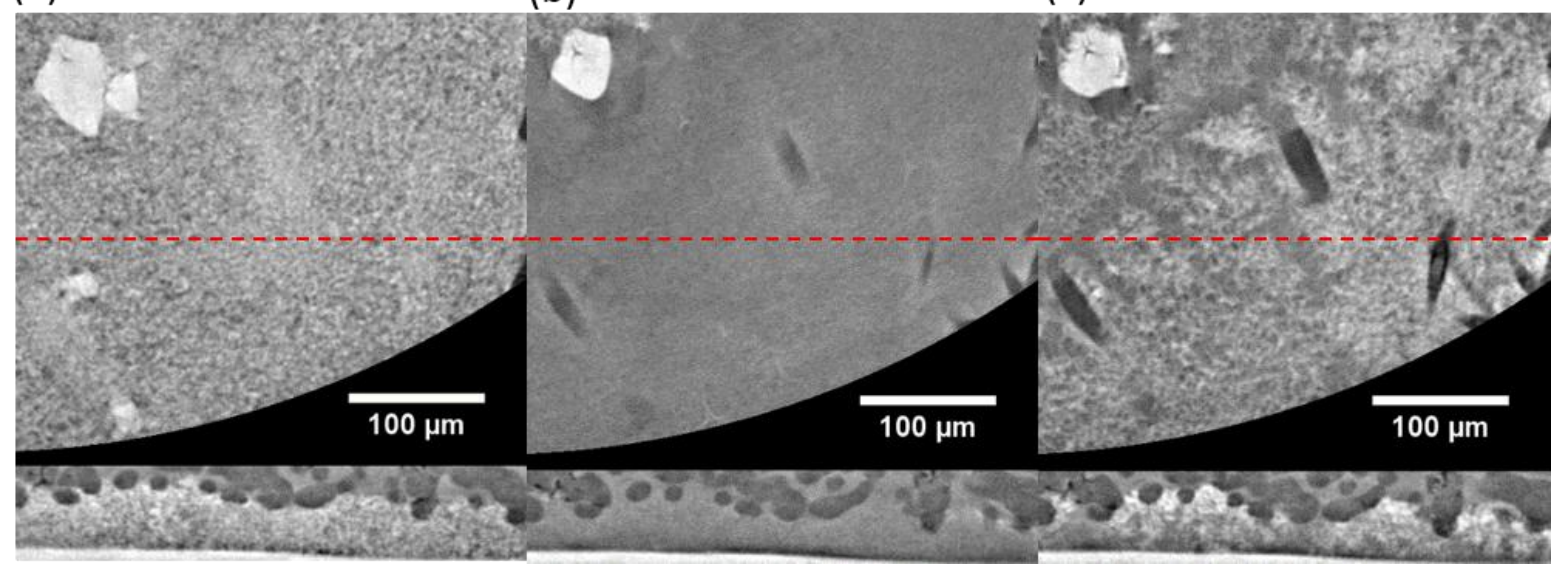

Figure 6. Lateral and transversal XRCT images focused on an electrochemically active zone of the electrode at (a) 0\% DOD, (b) 100\% DOD and (c) 100\% SOC of the $1^{\text {st }}$ cycle. The red dashed line in the lateral images corresponds to the position of the transversal images.

Figure 6a-c shows lateral and transversal XRCT slices focused on an electroactive zone of the electrode zone (delimited by the blue square in Figure 5b) at 0\% DOD, 100\% DOD and $100 \%$ SOC of the $1^{\text {st }}$ cycle. As seen in the transversal images, there is no evidence of collapsing of the electrode upon cycling. Actually, the decrease of the electrode thickness at 
the end of the $1^{\text {st }}$ discharge, determined from the transversal displacement of the separator fibers, is estimated at about $7-8 \mu \mathrm{m}$ (i.e. $\sim 10 \%$ of its initial thickness). This suggests that PDDA-TFSI is an efficient binder to preserve the electrode architecture despite the sulfur depletion. In comparison, with PVDF as a binder, a much larger decrease of the electrode thickness was noticed by G. Tonin ${ }^{39}$. Indeed, a decrease of about $80 \%$ of the electrode thickness was observed while discharging the cell, i.e. the electrode thickness decreased from $\sim 42 \mu \mathrm{m}$ at the pristine state to $\sim 9 \mu \mathrm{m}$ after the first quasi-plateau. In presence of PVdF binder, the electrode thickness evolution is in good accordance with the porosity created by reduction and dissolution of sulfur. Such electrode collapsing is not observed with the PDDA-TFSI binder, which may be associated with benefic interaction between the binder and the $\mathrm{CB}$ or sulfur compounds. In presence of PVdF binder, the electrode thickness evolution is in good accordance with the porosity created by reduction and dissolution of sulfur. Such electrode collapsing is not observed with the PDDA-TFSI binder, which may be associated with benefic interaction between the binder and the $\mathrm{CB}$ or sulfur compounds. More details on the volume expansion/contraction of sulfur-based electrodes depending on the binder nature (CMC, PVDF and PDDA-TFSI), evaluated by operando dilatometry, will be presented in a future article. Additionally, we can see in the transversal image of Figure 6c that the upper zone of the electrode near the separator is whiter, suggesting a preferential sulfur deposition at the electrode surface. 


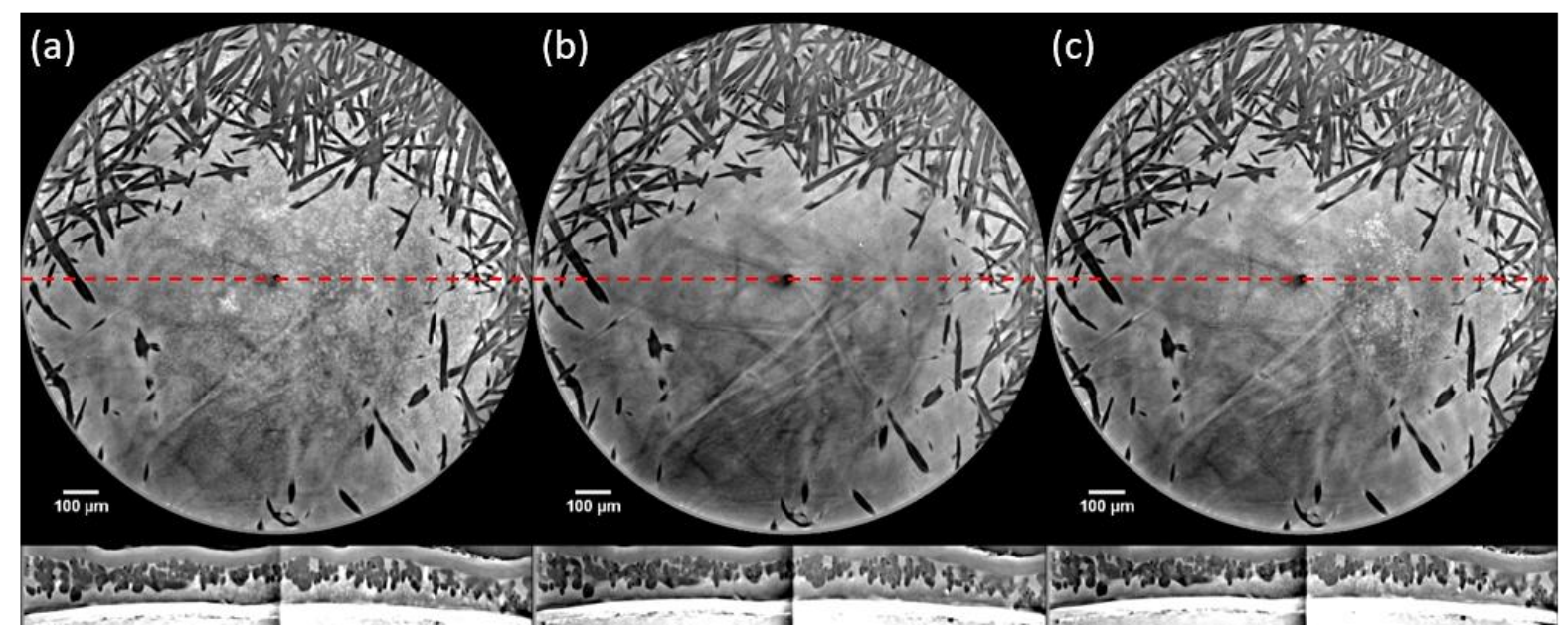

Figure 7. Lateral and transversal XRCT images of the electrode at (a) 0\% DOD, (b) 100\% DOD and (c) $100 \%$ SOC of the $11^{\text {th }}$ cycle. The red dashed line in the lateral images corresponds to the position of the transversal images

Figure 7a-c shows the same PDDA electrode during its $11^{\text {th }}$ cycle, at the same three states of discharge-charge as Figure 5. The chosen lateral slices are also at the interface between the electrode and the separator. Video S2 in supporting information shows the evolution of the electrode during the whole $11^{\text {th }}$ cycle. As described in the XRD section, most of the observable sulfur (light gray scarce areas) at the initial state $\left(0 \%\right.$ of DOD) of the $11^{\text {th }}$ cycle is now $\beta-S_{8}$. It can be seen that the deposition pattern that was visible at the end of the $1^{\text {st }}$ charge is now completely different. The inactive central zone is also not visible anymore. As seen in Video S2, the majority of the sulfur visible in Figure 7a is dissolved in the first 30 minutes of discharge, in accordance with the short duration of the first discharge plateau. In Figure $7 \mathbf{b}$, at $100 \%$ DOD, no elemental sulfur seems to be visible anymore, including the larger sulfur particles. This support our conclusion in the XRD section that the remaining $\alpha$ $\mathrm{S}_{8}$ of the $1^{\text {st }}$ cycle has progressively reacted during the subsequent cycles. Sulfur deposition at the end of the $11^{\text {th }}$ cycle is also observed (Figure 7c), showing again different patterns. Without pre-existing sulfur acting as preferential deposition sites, sulfur seems to be depositing in a random manner, perhaps dictated by the porosity and the carbon available surface of the carbon-binder domain, which cannot be seen on these images. Finally, even 
though XRD results seem to indicate the presence of solid crystalline $\mathrm{Li}_{2} \mathrm{~S}$, it cannot be observed in Figure $7 \mathbf{b}$ because of the nanometric size of $\mathrm{Li}_{2} \mathrm{~S}$.

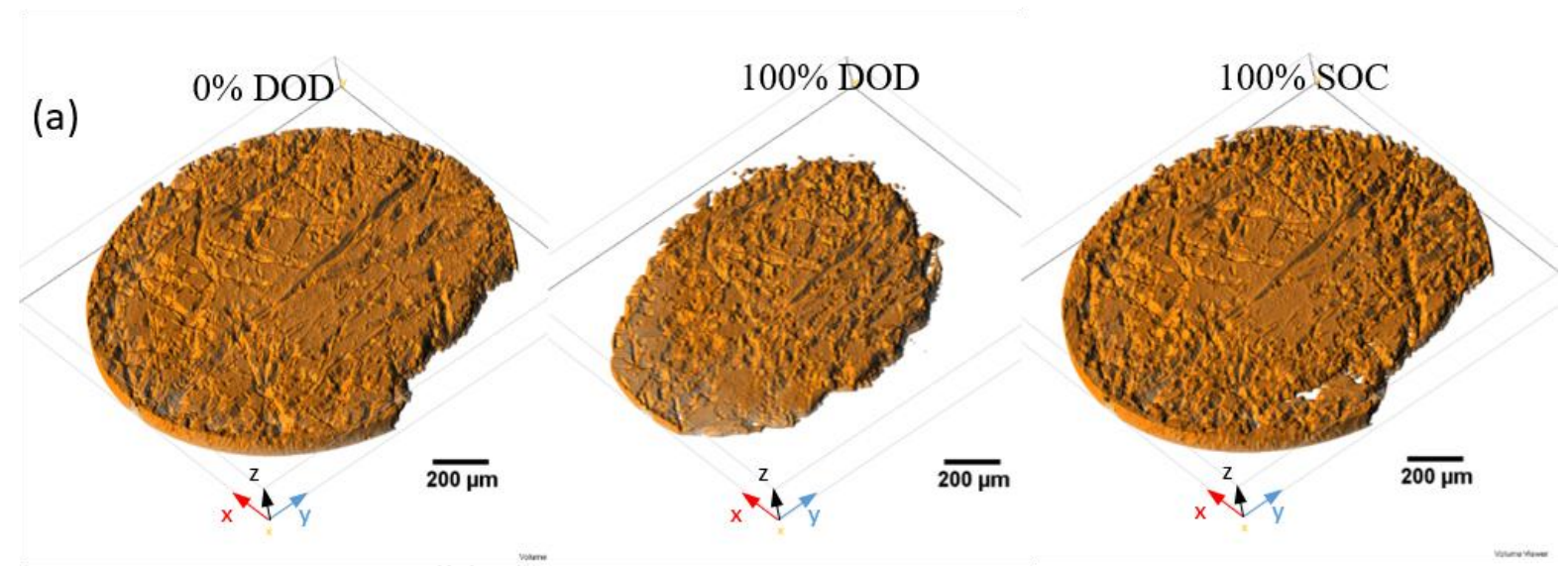

(b)

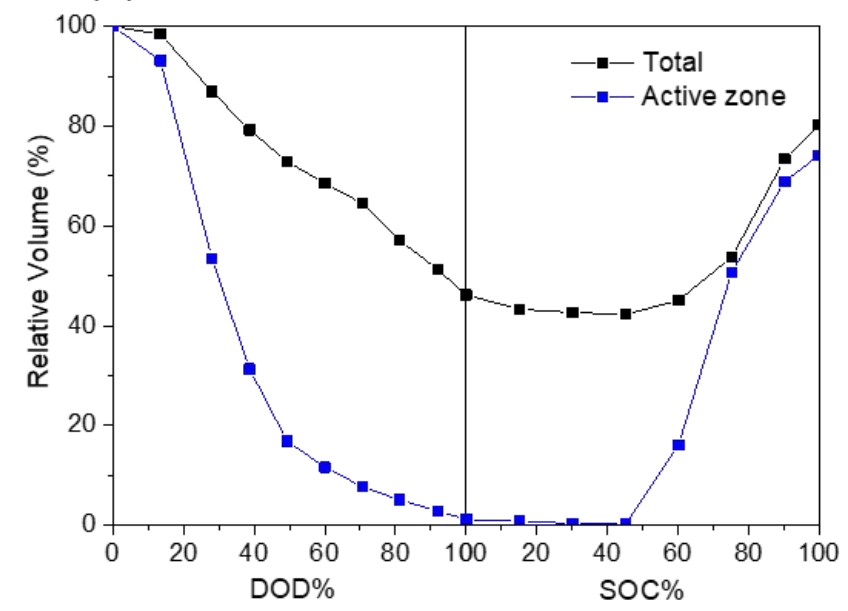

Figure 8. (a) 3D views of the sulfur-rich phase at 0\% DOD, 100\% DOD and 100\% SOC for the $1^{\text {st }}$ cycle, and (b) relative variation during the $1^{\text {st }}$ cycle of the sulfur-rich phase volume in the total analyzed electrode volume of $1433 \times 1433 \times 70 \mu^{3}$ (black curve) and in a selected active zone of $376 \times 333 \times 70 \mu^{3}$ (blue curve) shown in Fig.6.

Figure 8a shows reconstructed 3D views of the segmented sulfur-rich phase (including also the segmented large S particles) at different stages of the $1^{\text {st }}$ cycle for the total analyzed electrode volume of $1433 \times 1433 \times 70 \mu \mathrm{m}^{3}$. The segmented sulfur-free phase (i.e. porous carbon-binder domain filled with electrolyte) is set transparent in this rendering. Video S3 in supporting information shows the complete evolution in $3 \mathrm{D}$ view of the sulfur-rich phase during the $1^{\text {st }}$ cycle. From these segmentations, the relative volume variation of the sulfurrich phase during the $1^{\text {st }}$ cycle can be determined as shown in Figure $8 \mathbf{b}$ (black curve). Its volume is normalized at $100 \%$ for the initial state. Note that this black curve differs from the 
curve extracted from XRD analyses in Figure 4 because here both $\alpha-S_{8}$ and $\beta-S_{8}$ are involved. Moreover a large part (40\%) of the XRCT analyzed volume is non-active compared to $13 \%$ for the XRD analyses. Whereas in theory the elemental sulfur dissolution only occurs during the first discharge plateau, it can be seen here that the volume fraction of sulfur constantly decreases during the discharge. This may be considered as a side effect of the incomplete sulfur reduction in the electrode. It can even be observed that some of the remaining sulfur at the end of the discharge keeps dissolving by contact with the electrolyte at the beginning of the charge. At $100 \%$ SOC, the recovered volume of the sulfur-rich phase is calculated about $80 \%$, i.e. a $20 \%$ loss compared to the initial state. Considering that only $87 \%$ of the whole electrode was active during the discharge (from the previously calculated $13 \%$ inactive volume), we can estimate a $\sim 69 \%$ recovery. Even though it remains biased by the fact that only a portion of the electrode is observed, this value is close to the CE value of $71 \%$ calculated from the discharge and charge capacities of the electrode at the $1^{\text {st }}$ cycle $(660$ and $470 \mathrm{mAh} \mathrm{g}^{-1}$, respectively). A similar segmentation procedure was performed on the selected electroactive area shown in Figure $\mathbf{6}$ and the relative volume variation of the segmented sulfur-rich phase in this active domain is presented in Figure $\mathbf{8 b}$ (blue curve). Here, the volume variation of the sulfur-rich phase follows a trend in better agreement with the theory, which predicts that the sulfur reduction occurs mainly during the $1^{\text {st }}$ discharge plateau. The volume of the sulfur phase decreases sharply down to $40-50 \%$ of DOD. The remaining volume belongs for the most part to the large sulfur particle included in the selected area, which does not dissolve completely. Then, the volume stays under 5\% until $50 \%$ of SOC and finally increases again until it reaches a value of $\sim 74 \%$ at $100 \%$ of SOC. 


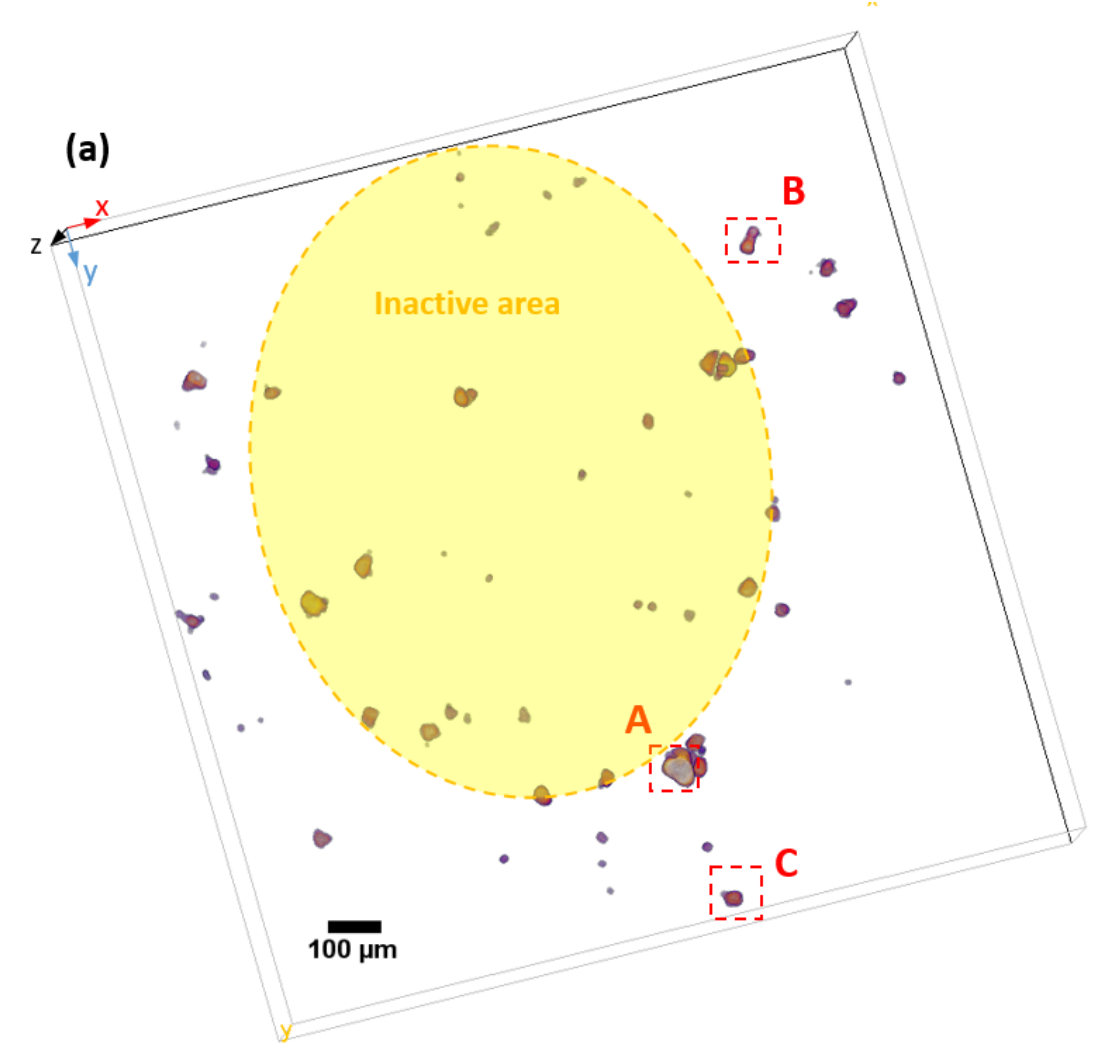

(b)

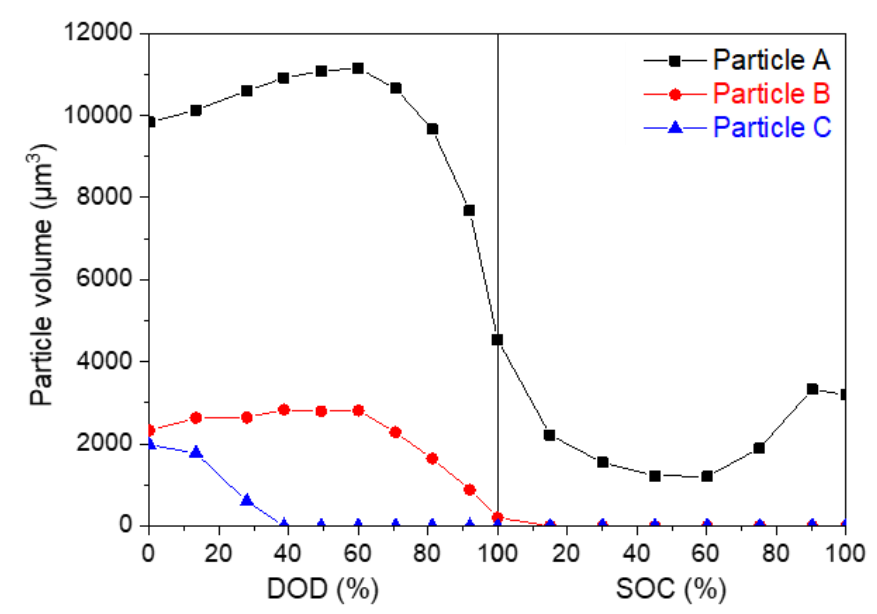

Figure 9. (a) $3 D$ view of the segmented sulfur particles in the electrode and (b) evolution of the volume of selected particles $A, B$ and $C$ during the $1^{\text {st }}$ cycle

Figure 9a shows a reconstructed 3D view of the large sulfur particles in the electrode at the initial state after removing all other phases. Video S4 in supporting information show their evolution during the $1^{\text {st }}$ cycle. This allows for the quantification of the volume evolution of individual large sulfur particles in the electrode. For this purpose, three sulfur particles have been selected in the electrochemically active zone as indicated in Figure 9a: particle $A$ 
is the largest particle of a cluster located at the edge of the inactive zone at the surface of the electrode, particle $B$ is also located at the edge of the inactive zone but closer to the current collector (lower $z$ position); and particle $C$ is located further away from the central inactive zone at the electrode surface. All the large particles located inside the inactive zone see no change in their morphology. Figure $9 \mathbf{b}$ describes the evolution of the volume of the $A, B$ and $C$ particles during the $1^{\text {st }}$ cycle. It can be seen that particle $A$, which is the largest and the closest to the inactive zone, does not start dissolving until $\sim 60 \%$ of DOD. Moreover, it continues to dissolve at the beginning of the charge, probably by redox reaction with the polysulfides present in the electrolyte, until reaching a minimal volume value of about 1200 $\mu \mathrm{m}^{3}$, corresponding to $\sim 12 \%$ of its initial volume. From $\sim 60 \%$ of SOC, its volume starts increasing again due to the oxidation of polysulfides into sulfur to reach $3200 \mu \mathrm{m}^{3}$ at the end of the charge. This tends to support our earlier claim that remaining sulfur acts as nucleation site during sulfur electrodeposition at the end of the charge. Particle $B$ follows a similar trend, also being located at the edge of the inactive zone, with a dissolution starting $~ 60 \%$ of DOD. Due to its lower initial volume, particle $B$ is nearly completely dissolved at the end of the discharge, confirming the major impact of the initial size of the sulfur on their electrodissolution rate. However, the absence of large $S$ particles at the $11^{\text {th }}$ cycle suggests they are fully dissolved within a few cycles. Particle $C$, having an initial volume similar to particle $B$ but being further away from the inactive central zone, dissolves almost immediately and completely during the first $40 \%$ of DOD. This confirms the major impact of the position of the S particles in the lateral $\mathrm{x}-\mathrm{y}$ plan on their electrodissolution rate in the cell investigated. In contrast, on the basis of the present XRCT data, this is no clear evidence that the transversal position of the $\mathrm{S}$ particles in the electrode influences significantly their dissolution rate. However, keeping in mind the presence of a large non-electroactive area due to a weak contact on the current collector in the present synchrotron cell, further observations 
would be needed to draw more conclusions on the dissolution kinetics of sulfur particles depending on their localisation in the electrode.

\section{Conclusions}

This study has confirmed that sulfur electrodes using PDDA-TFSI polyelectrolyte as a binder performs much better than with conventional CMC or PVdF binders in terms of initial capacity and capacity retention with cycling. Even though the role of PDDA-TFSI could not be clearly pointed out, mostly because of spatial and contrast resolution limitation, this work is one of the few currently existing investigations on $\mathrm{Li} / \mathrm{S}$ electrodes using synchrotron XRD and XRCT. Some phenomena were observed directly for the first time, such as the growing of part of the crystalline sulfur on the residual sulfur in parallel to the growing of new sulfur particles, and the fact that the crystalline form of sulfur appears to be directly associated with the presence of pre-existing sulfur. Indeed $\alpha-S_{8}$ are forming on the pre-existing $\alpha-S_{8}$ whereas the expected $\beta-S_{8}$ are formed elsewhere. This work also points out the importance of electrode homogeneity and flatness as differences in reactivity kinetic was noticed depending on the particle position inside the electrode, as well as an overall space-dependence of $\mathrm{S}$ dissolution (dissolution front) during discharge. Moreover, the absence of electrode collapsing in the sulfur-depleted zones, contrarily to what was observed with PVDF binder in literature, suggests that the present polyelectrolyte is an efficient binder to preserve the electrode architecture upon cycling. Thus, this work paves the way for further investigation on the mechanical properties of polyelectrolyte-type binders for sulfur-based electrodes through advanced operando characterization techniques, while highlighting some new phenomena as mentioned above. 


\section{Supporting Information}

Evolution of the XRD patterns along the vertical axis of the cell, videos of lateral and transversal XRCT images of the PDDA electrode acquired during the $1^{\text {st }}$ and $11^{\text {th }}$ cycles, video of the sulfur-rich phase in $3 \mathrm{D}$ view during the $1^{\text {st }}$ cycle, video of large $\mathrm{S}$ particles in $3 \mathrm{D}$ view during the $1^{\text {st }}$ cycle.

\section{Acknowledgements}

The authors thank the Natural Sciences and Engineering Research Council (NSERC) of Canada (Grant No. RGPIN-2016-04524) and the Auvergne Rhône-Alpes region (ADR ARC $\left.2016 \mathrm{~N}^{\circ} 16-005614-01\right)$ for supporting this work. We also thank the ESRF synchrotron's reviewing committee for shifts allocation and the beamline scientists of ID11, M. Majkut, J. Wright and C. Nemoz. The author gives a special thought to D. Devaux, L. Magnier and Q. Saby for their precious help and support during the in situ XRCT/XRD experiments and to V. Vanpeene for his help with the XRCT data analysis. 


\section{References}

(1) Olivetti, E. A.; Ceder, G.; Gaustad, G. G.; Fu, X. Lithium-Ion Battery Supply Chain Considerations: Analysis of Potential Bottlenecks in Critical Metals. Joule 2017, 1 (2), 229-243. https://doi.org/10.1016/j.joule.2017.08.019.

(2) Bruce, P. G.; Freunberger, S. A.; Hardwick, L. J.; Tarascon, J.-M. Li-O $\mathrm{O}_{2}$ and Li-S Batteries with High Energy Storage. Nature Materials 2012, 11 (1), 19-29. https://doi.org/10.1038/nmat3191.

(3) Choi, N.-S.; Chen, Z.; Freunberger, S. A.; Ji, X.; Sun, Y.-K.; Amine, K.; Yushin, G.; Nazar, L. F.; Cho, J.; Bruce, P. G. Challenges Facing Lithium Batteries and Electrical Double-Layer Capacitors. Angewandte Chemie International Edition 2012, 51 (40), 9994-10024. https://doi.org/10.1002/anie.201201429.

(4) Barchasz, C.; Molton, F.; Duboc, C.; Leprêtre, J.-C.; Patoux, S.; Alloin, F. Lithium/Sulfur Cell Discharge Mechanism: An Original Approach for Intermediate Species Identification. Anal. Chem. 2012, $84 \quad$ (9), 3973-3980. https://doi.org/10.1021/ac2032244.

(5) Kim, J.-K. Hybrid Gel Polymer Electrolyte for High-Safety Lithium-Sulfur Batteries. Materials Letters 2017, 187, 40-43. https://doi.org/10.1016/j.matlet.2016.10.069.

(6) Tang, H.; Yao, S.; Mi, J.; Wu, X.; Hou, J.; Shen, X. Ketjen Black/Mg0.6Ni0.4O Composite Coated Separator for Lithium-Sulfur Batteries with Enhanced Electrochemical Performance. Materials Letters 2017, 186, 127-130. https://doi.org/10.1016/j.matlet.2016.09.102.

(7) An, Y. ling; Song, W.; Wei, P.; Fan, M.; Chen, H.; Ju, Q.; Chen, D.; Tian, G.; Lv, C.; Shu, K. Polyaniline-Wrapping Hollow Sulfur with MCM-41 Template and Improved Capacity and Cycling Performance of Lithium Sulfur Batteries. Renewable Energy 2016, 99, 289-294. https://doi.org/10.1016/j.renene.2016.06.062. 
(8) Andreeva, D. V.; Skorb, E. V.; Shchukin, D. G. Layer-by-Layer Polyelectrolyte/Inhibitor Nanostructures for Metal Corrosion Protection. ACS Appl. Mater. Interfaces 2010, 2 (7), 1954-1962. https://doi.org/10.1021/am1002712.

(9) Skorb, E. V.; Fix, D.; Andreeva, D. V.; Möhwald, H.; Shchukin, D. G. SurfaceModified Mesoporous SiO2 Containers for Corrosion Protection. Advanced Functional Materials 2009, 19 (15), 2373-2379. https://doi.org/10.1002/adfm.200801804.

(10) Li, L.; Pascal, T. A.; Connell, J. G.; Fan, F. Y.; Meckler, S. M.; Ma, L.; Chiang, Y.-M.; Prendergast, D.; Helms, B. A. Molecular Understanding of Polyelectrolyte Binders That Actively Regulate Ion Transport in Sulfur Cathodes. Nat Commun 2017, 8 (1), 110. https://doi.org/10.1038/s41467-017-02410-6.

(11) Lin, F.; Liu, Y.; Yu, X.; Cheng, L.; Singer, A.; Shpyrko, O. G.; Xin, H. L.; Tamura, N.; Tian, C.; Weng, T.-C.; Yang, X.-Q.; Meng, Y. S.; Nordlund, D.; Yang, W.; Doeff, M. M. Synchrotron X-Ray Analytical Techniques for Studying Materials Electrochemistry in Rechargeable Batteries. Chem. Rev. 2017, 117 (21), 13123-13186. https://doi.org/10.1021/acs.chemrev.7b00007.

(12) Liu, X.-C.; Zhou, S. P.; Liu, M.; Xu, G.-L.; Zhou, X.-D.; Huang, L.; Sun, S.-G.; Amine, K.; Ke, F.-S. Utilizing a Metal as a Sulfur Host for High Performance Li-S Batteries. Nano Energy $2018, \quad 50, \quad 685-690$. https://doi.org/10.1016/j.nanoen.2018.06.011.

(13) Paolella, A.; Zhu, W.; Marceau, H.; Kim, C.; Feng, Z.; Liu, D.; Gagnon, C.; Trottier, J.; Abdelbast, G.; Hovington, P.; Vijh, A.; Demopoulos, G. P.; Armand, M.; Zaghib, K. Transient Existence of Crystalline Lithium Disulfide Li2S2 in a Lithium-Sulfur Battery. Journal of Power Sources 2016, 325, 641-645. https://doi.org/10.1016/j.jpowsour.2016.06.086. 
(14) Jha, H.; Buchberger, I.; Cui, X.; Meini, S.; Gasteiger, H. A. Li-S Batteries with Li2S Cathodes and Si/C Anodes. J. Electrochem. Soc. 2015, 162 (9), A1829-A1835. https://doi.org/10.1149/2.0681509jes.

(15) Zhu, W.; Paolella, A.; Kim, C.-S.; Liu, D.; Feng, Z.; Gagnon, C.; Trottier, J.; Vijh, A.; Guerfi, A.; Mauger, A.; Julien, C. M.; Armand, M., Zaghib, K. Investigation of the Reaction Mechanism of Lithium Sulfur Batteries in Different Electrolyte Systems by in Situ Raman Spectroscopy and in Situ X-Ray Diffraction. Sustainable Energy Fuels 2017, 1 (4), 737-747. https://doi.org/10.1039/C6SE00104A.

(16) Waluś, S.; Barchasz, C.; Bouchet, R.; Leprêtre, J.-C.; Colin, J.-F.; Martin, J.-F.; Elkaïm, E.; Baehtz, C.; Alloin, F. Lithium/Sulfur Batteries Upon Cycling: Structural Modifications and Species Quantification by In Situ and Operando X-Ray Diffraction Spectroscopy. Advanced Energy Materials 2015, $5 \quad$ (16), 1500165. https://doi.org/10.1002/aenm.201500165.

(17) Conder, J.; Bouchet, R.; Trabesinger, S.; Marino, C.; Gubler, L.; Villevieille, C. Direct Observation of Lithium Polysulfides in Lithium-Sulfur Batteries Using Operando X-

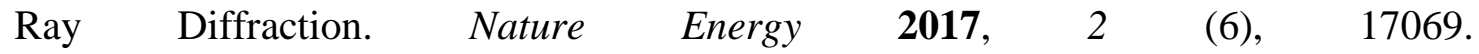
https://doi.org/10.1038/nenergy.2017.69.

(18) Cañas, N. A.; Wolf, S.; Wagner, N.; Friedrich, K. A. In-Situ X-Ray Diffraction Studies of Lithium-Sulfur Batteries. Journal of Power Sources 2013, 226, 313-319. https://doi.org/10.1016/j.jpowsour.2012.10.092.

(19) Yu, S.-H.; Huang, X.; Schwarz, K.; Huang, R.; Arias, T. A.; Brock, J. D.; Abruña, H. D. Direct Visualization of Sulfur Cathodes: New Insights into Li-S Batteries via Operando X-Ray Based Methods. Energy Environ. Sci. 2018, 11 (1), 202-210. https://doi.org/10.1039/C7EE02874A. 
(20) Villevieille, C.; Wang, X.-J.; Krumeich, F.; Nesper, R.; Novák, P. MoS2 Coating on MoO3 Nanobelts: A Novel Approach for a High Specific Charge Electrode for Rechargeable Li-Ion Batteries. Journal of Power Sources 2015, 279, 636-644. https://doi.org/10.1016/j.jpowsour.2014.12.129.

(21) Dörfler, S.; Strubel, P.; Jaumann, T.; Troschke, E.; Hippauf, F.; Kensy, C.; Schökel, A.; Althues, H.; Giebeler, L.; Oswald, S.; Kaskel, S. On the Mechanistic Role of Nitrogen-Doped Carbon Cathodes in Lithium-Sulfur Batteries with Low Electrolyte Weight Portion. Nano Energy 2018, 54, 116-128. https://doi.org/10.1016/j.nanoen.2018.09.065.

(22) Waluś, S.; Barchasz, C.; Bouchet, R.; Martin, J.-F.; Leprêtre, J.-C.; Alloin, F. NonWoven Carbon Paper as Current Collector for Li-Ion/Li2S System: Understanding of the First Charge Mechanism. Electrochimica Acta 2015, 180, 178-186. https://doi.org/10.1016/j.electacta.2015.08.114.

(23) Waluś, S.; Barchasz, C.; Colin, J.-F.; Martin, J.-F.; Elkaïm, E.; Leprêtre, J.-C.; Alloin, F. New Insight into the Working Mechanism of Lithium-Sulfur Batteries: In Situ and Operando X-Ray Diffraction Characterization. Chem. Commun. 2013, 49 (72), 78997901. https://doi.org/10.1039/C3CC43766C.

(24) Huang, S.; Lim, Y. V.; Zhang, X.; Wang, Y.; Zheng, Y.; Kong, D.; Ding, M.; Yang, S. A.; Yang, H. Y. Regulating the Polysulfide Redox Conversion by Iron Phosphide Nanocrystals for High-Rate and Ultrastable Lithium-Sulfur Battery. Nano Energy 2018, 51, 340-348. https://doi.org/10.1016/j.nanoen.2018.06.052.

(25) Vanpeene, V.; King, A.; Maire, E.; Roué, L. In Situ Characterization of Si-Based Anodes by Coupling Synchrotron X-Ray Tomography and Diffraction. Nano Energy 2019, 56, 799-812. https://doi.org/10.1016/j.nanoen.2018.11.079. 
(26) Vanpeene, V.; Villanova, J.; King, A.; Lestriez, B.; Maire, E.; Roué, L. Dynamics of the Morphological Degradation of Si-Based Anodes for Li-Ion Batteries Characterized by In Situ Synchrotron X-Ray Tomography. Advanced Energy Materials 2019, 9 (18), 1803947. https://doi.org/10.1002/aenm.201803947.

(27) P. Finegan, D.; Scheel, M.; B. Robinson, J.; Tjaden, B.; Michiel, M. D.; Hinds, G.; L. Brett, D. J.; R. Shearing, P. Investigating Lithium-Ion Battery Materials during Overcharge-Induced Thermal Runaway: An Operando and Multi-Scale X-Ray CT Study. Physical Chemistry Chemical Physics 2016, 18 (45), 30912-30919. https://doi.org/10.1039/C6CP04251A.

(28) Pietsch, P.; Hess, M.; Ludwig, W.; Eller, J.; Wood, V. Combining Operando Synchrotron X-Ray Tomographic Microscopy and Scanning X-Ray Diffraction to Study Lithium Ion Batteries. Scientific Reports 2016, 6, 27994. https://doi.org/10.1038/srep27994.

(29) Yermukhambetova, A.; Tan, C.; Daemi, S. R.; Bakenov, Z.; Darr, J. A.; Brett, D. J. L.; Shearing, P. R. Exploring 3D Microstructural Evolution in Li-Sulfur Battery Electrodes Using in-Situ X-Ray Tomography. Scientific Reports 2016, 6, 35291. https://doi.org/10.1038/srep35291.

(30) Zielke, L.; Barchasz, C.; Waluś, S.; Alloin, F.; Leprêtre, J.-C.; Spettl, A.; Schmidt, V.; Hilger, A.; Manke, I.; Banhart, J.; Zengerle, R.; Thiele, S. Degradation of Li/S Battery Electrodes On 3D Current Collectors Studied Using X-Ray Phase Contrast Tomography. Scientific Reports 2015, 5, 10921. https://doi.org/10.1038/srep10921.

(31) Tonin, G.; Vaughan, G.; Bouchet, R.; Alloin, F.; Michiel, M. D.; Boutafa, L.; Colin, J.F.; Barchasz, C. Multiscale Characterization of a Lithium/Sulfur Battery by Coupling Operando X-Ray Tomography and Spatially-Resolved Diffraction. Scientific Reports 2017, 7 (1), 2755. https://doi.org/10.1038/s41598-017-03004-4. 
(32) Pont, A.-L.; Marcilla, R.; De Meatza, I.; Grande, H.; Mecerreyes, D. PyrrolidiniumBased Polymeric Ionic Liquids as Mechanically and Electrochemically Stable Polymer Electrolytes. Journal of Power Sources 2009, 188 (2), 558-563. https://doi.org/10.1016/j.jpowsour.2008.11.115.

(33) Lemarié, Q.; Alloin, F.; Thivel, P. X.; Idrissi, H.; Roué, L. Study of Sulfur-Based Electrodes by Operando Acoustic Emission. Electrochimica Acta 2019, 299, 415-422. https://doi.org/10.1016/j.electacta.2019.01.019.

(34) Labiche, J.-C.; Mathon, O.; Pascarelli, S.; Newton, M. A.; Ferre, G. G.; Curfs, C.; Vaughan, G.; Homs, A.; Carreiras, D. F. Invited Article: The Fast Readout Low Noise Camera as a Versatile x-Ray Detector for Time Resolved Dispersive Extended x-Ray Absorption Fine Structure and Diffraction Studies of Dynamic Problems in Materials Science, Chemistry, and Catalysis. Review of Scientific Instruments 2007, 78 (9), 091301. https://doi.org/10.1063/1.2783112.

(35) Mirone, A.; Brun, E.; Gouillart, E.; Tafforeau, P.; Kieffer, J. The PyHST2 Hybrid Distributed Code for High Speed Tomographic Reconstruction with Iterative Reconstruction and a Priori Knowledge Capabilities. Nuclear Instruments and Methods in Physics Research Section B: Beam Interactions with Materials and Atoms 2014, 324, 41-48. https://doi.org/10.1016/j.nimb.2013.09.030.

(36) Schindelin, J.; Arganda-Carreras, I.; Frise, E.; Kaynig, V.; Longair, M.; Pietzsch, T.; Preibisch, S.; Rueden, C.; Saalfeld, S.; Schmid, B.; Tinevez, J.-Y.; White, D. J.; Hartenstein, V.; Eliceiri, K.; Tomancak, P.; Cardona, A. Fiji: An Open-Source Platform for Biological-Image Analysis. Nat. Methods 2012, 9 (7), 676-682. https://doi.org/10.1038/nmeth.2019.

(37) Waluś, S.; Robba, A.; Bouchet, R.; Barchasz, C.; Alloin, F. Influence of the Binder and Preparation Process on the Positive Electrode Electrochemical Response and Li/S 
System Performances. Electrochimica Acta 2016, 210, 492-501. https://doi.org/10.1016/j.electacta.2016.05.130.

(38) Kulisch, J.; Sommer, H.; Brezesinski, T.; Janek, J. Simple Cathode Design for Li-S Batteries: Cell Performance and Mechanistic Insights by in Operando X-Ray Diffraction. Physical Chemistry Chemical Physics 2014, 16 (35), 18765-18771. https://doi.org/10.1039/C4CP02220C.

(39) Tonin, G. Li/S accumulators: Electrochemical mechanism investigation using operando analysis by absorption and X-ray diffraction tomography. $\mathrm{PhD}$ Thesis, University Grenoble Alpes, 2019. HAL Id: tel-02284930 https://tel.archives-ouvertes.fr/tel02284930. 


\section{TOC graphic}
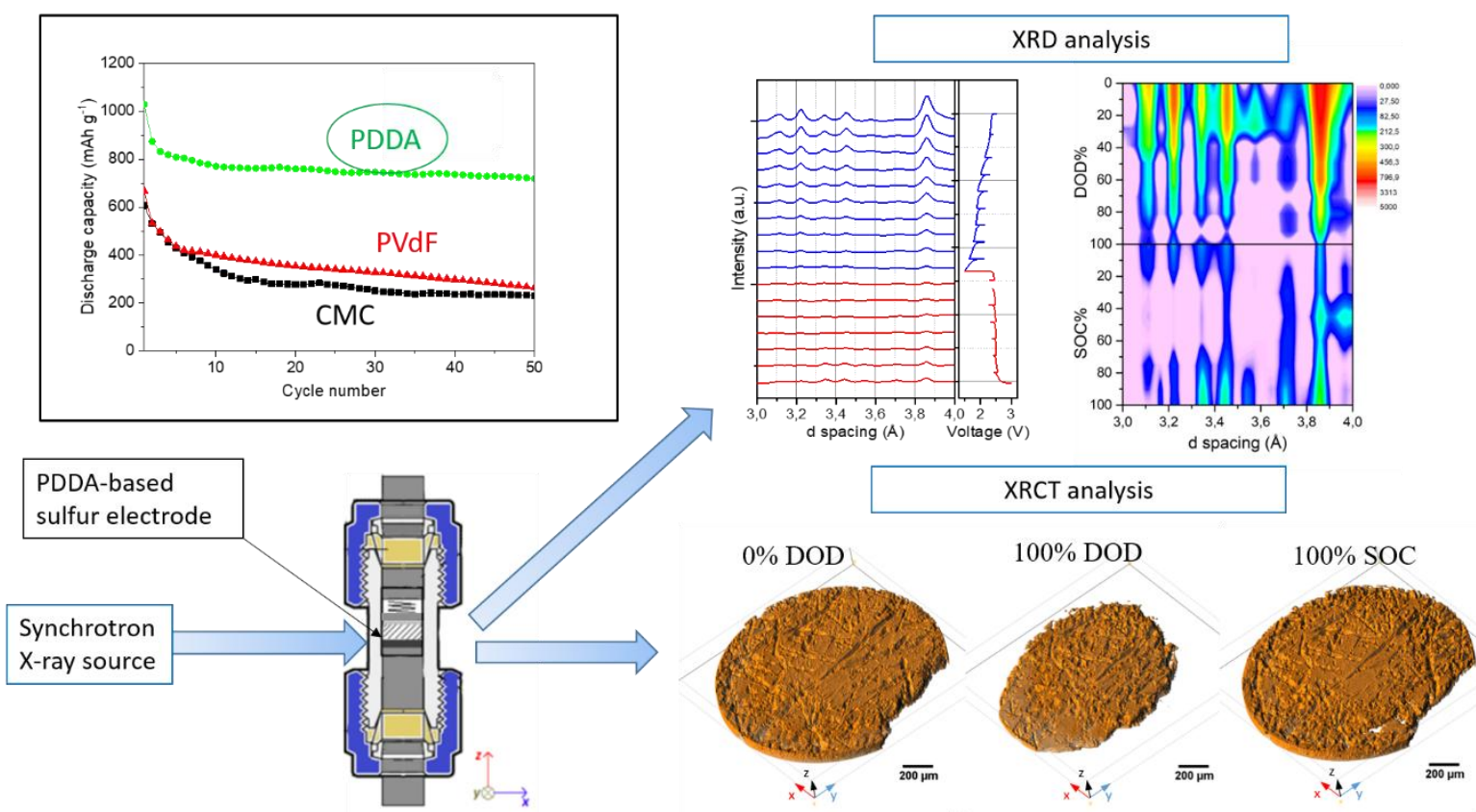

(b) 